\title{
Air pollutants, economic growth and public health: implications for sustainable development in OECD countries
}

\author{
Ghulam Mujtaba $^{1,2} \cdot$ Syed Jawad Hussain Shahzad ${ }^{3,4}$ \\ Received: 14 September 2020 / Accepted: 11 October 2020 / Published online: 21 October 2020 \\ (C) Springer-Verlag GmbH Germany, part of Springer Nature 2020
}

\begin{abstract}
The rapid economic growth over recent years and the resulting environmental pollution in OECD countries are a serious concern for the health of the general public. A comprehensive analysis of environmental pollutants, economic growth, and public health is done using data from 28 OECD economies from 2002 to 2018. Panel fully modified least squares and the panel vector error correction model are used. The results show that there is long-run causality from renewable energy and carbon dioxide $\left(\mathrm{CO}_{2}\right)$ emissions to healthcare spending. Renewable energy and healthcare spending are positively and significantly related. It is concluded that investment in renewable energy leads to a reduction in air pollution, improvements in healthcare, and the promotion of economic growth.
\end{abstract}

Keywords Air pollutants $\cdot$ OECD economies $\cdot$ Public health expenditure $\cdot$ Renewable energy

\section{Introduction}

In the last few years, tremendous growth in the healthcare industry has been seen for various economic, noneconomic, and environmental reasons, which is a serious concern for health economists, policymakers, and researchers. There are two views regarding healthcare expense. One group of researchers (Azam et al. 2019) believe that healthcare expenditure is a luxury, like a commodity, so it is necessary to rely on market forces. Another group (Chaabouni and Saidi 2017; Ye and Zhang 2018; Wang et al. 2019) believe that healthcare expenditure is necessary, and the government should intervene. Although significant spending on healthcare is

Responsible editor: Nicholas Apergis

Syed Jawad Hussain Shahzad j.syed@montpellier-bs.com

Ghulam Mujtaba

mujtaba.kayani786@gmail.com

1 School of Finance, Hubei University of Economics, Wuhan, People's Republic of China

2 Department of Management Science, COMSATS University Islamabad, Islamabad, Pakistan

3 Montpellier Business School, Montpellier, France

4 South Ural State University, Chelyabinsk, Russia necessary for economic development, excessive spending leads to an extra burden on government finances. Healthcare spending in the Organization for Economic Cooperation and Development (OECD) countries has shown a tremendously increasing trend. OECD countries spend almost $85 \%$ of world spending on health, while the population of those countries is less than $20 \%$ of the world total (Blázquez-Fernández et al. 2019). OECD countries have the highest healthcare expenditure in the world.

Figure 1 shows that, over time, healthcare expenditure increased gradually in OECD countries. In 2003 it was about $7.8 \%$ of gross domestic product (GDP), which increased to $8.8 \%$ in 2018, and is expected to reach $10.2 \%$ by 2030 (OECD 2019). One of the major challenges faced by the OECD is this continuous increase in healthcare expenses as a percentage of GDP.

Figure 2 shows is a comparison between healthcare expenditure of the United States (US) and the other OECD countries. The graph shows that before 2007, the US had higher health expenditure compared to the OECD as a whole, and after 2007, there was a decrease in health expenditure due to its high cost, few people were able to cover the private health care which has ultimately reduced the health expenditure growth.

The recent COVID-19 pandemic exerts pressure on healthcare expenditure, which has risen drastically (Apergis et al. 2020). In the United Kingdom (UK), it has risen to about $10 \%$ of GDP. As the infection spreads, it puts an excessive 
Fig. 1 Healthcare expenditure percentage of GDP, source: OECD Database of 2019

\section{Healthcare expenditure \% of GDP}

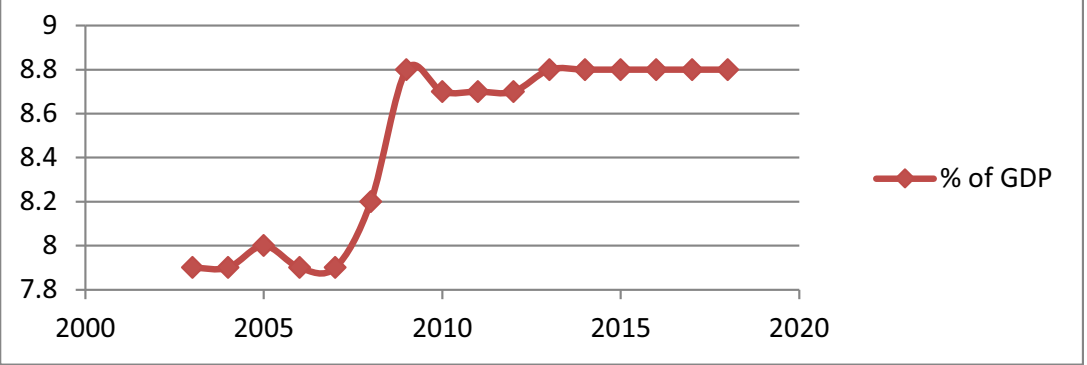

burden on the healthcare system. There is a limited supply of resources such as medical staff, hospital beds, protective suits, and ventilators (Bénassy-Quéré et al. 2020).

According to OECD Health Statistics (2019), during COVID-19, the OECD countries face the problem of critical bed capacity for the population, with Mexico in the lowest category. On average over one-fifth of health spending comes from private financing, while, in the case of treatment of COVID-19, about a quarter of financing comes from households themselves.

There are some positive effects of increasing healthcare expenses such as reduced illness and increased numbers of jobs, but unnecessary spending on healthcare means cuts have to be made elsewhere. Air pollution badly affects health and leads to an increase in healthcare expenditure. Pollutants include sulfur dioxide, carbon monoxide, and nitrogen dioxide, which cause respiratory diseases, pulmonary problems, asthma, food allergies, bronchitis, reduced lung growth, lung cancer, and reduced life expectancy (Sekar et al. 2016; Xie et al. 2018; Ma et al. 2018). It is necessary to identify the major drivers of healthcare spending, which include environmental deterioration (air pollution), along with other economic (e.g., GDP, foreign direct investment (FDI) inflow) and noneconomic (e.g., education) factors. In the long run, there is a direct positive connection between health and education. Improved health is a significant feature in enhancing the productivity of the labor force. Investment in health and education leads to improved health and a higher level of education (Ross and $\mathrm{Wu}$
1995). Healthcare expenses are rising gradually in OECD countries. GDP is an important variable for the estimation of healthcare spending. In OECD countries, it is forecast that, due to more stringent healthcare policies, there is to be a drastic decrease in healthcare expenditure (Akca et al. 2017). Increased healthcare expenditure is not solely by design, to improve health conditions, many factors contribute to healthcare expenses, such as the socioeconomic conditions, population, and the proportion of budget allocated to healthcare. The most important determinants of healthcare include GDP and the level of education in a country (Mirmirani et al. 2008).

According to Mirmirani et al. (2008), health conditions are not only determined by healthcare expenditure, but various other aspects impact the healthcare system of countries, such as the number of citizens, the area of the country, and the fiscal balance spent on healthcare which might fluctuate. Some countries with low incomes have strong health systems, which along with GDP and education make health an important indicator of prosperity.

In Fig. 3, healthcare funding is divided into public and private financing. Public financing includes health insurance and government expenditure, while private financing includes individuals' out of pocket payments and finances from corporations and NGOs. In OECD countries, there is more public spending than private. Nearly all populations in all OECD countries are provided with healthcare coverage. Mexico has the lowest health coverage as a proportion of population,

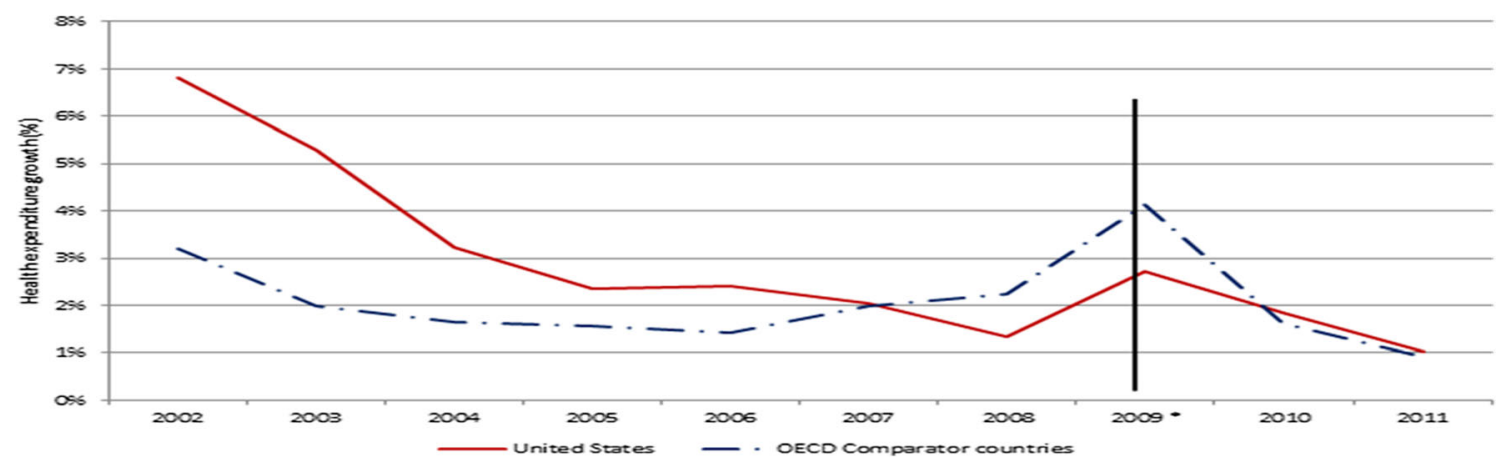

Fig. 2 Healthcare expenditure in OECD countries, source: OECD Health Statistics 2013 


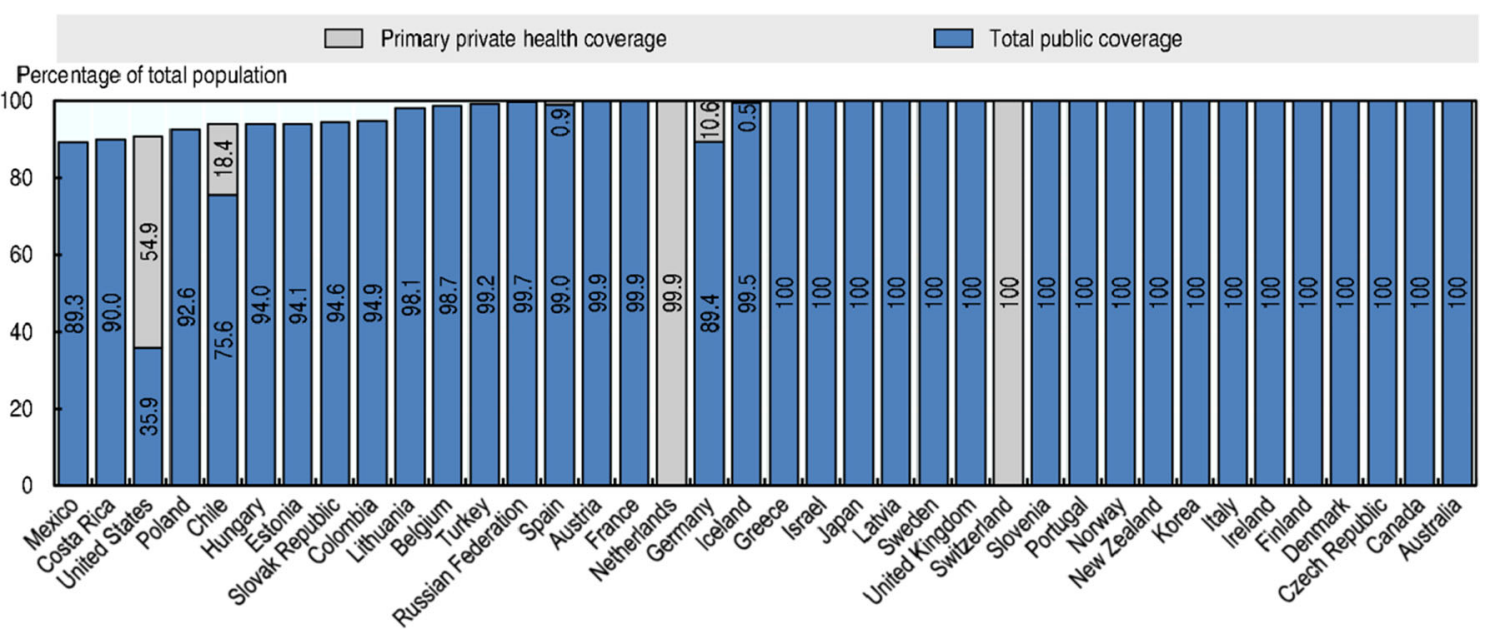

Fig. 3 Healthcare expenditure per capita across OECD countries, source: OECD Health Statistics (2019)

while the US has most private health coverage compared to public coverage. Switzerland and the Netherlands provide nearly $100 \%$ health coverage through private financing.

Breathing clean air is a crucial issue in this era. Continuous or increasing emissions of greenhouse gases exert severe pressure on the environment and health. Healthcare expenditure increases with environmental degradation. Many studies (Kais and Sami 2016; Yazdi and Khanalizadeh 2017) explore ecological degradation and how healthcare costs can be controlled. A major cause of environmental degradation is air pollution (Chaabouni et al. 2016). Air pollution has three types of effect. Firstly, various studies show that mortality rates have a direct connection to air pollution. In other words, when air pollution increases in an environment, it has an adverse impact on human health, in both developed and developing countries ( $\mathrm{Li}$ et al. 2019; Kayani et al. 2020). Approximately 3.3 million people die annually in the world due to air pollution in the atmosphere (Darçın 2017). Secondly, ill health caused by air pollution leads to increased healthcare expenditure and adversely affects labor productivity. When productivity decreases, domestic output also decreases and the whole economic cycle slows down (Mehrara et al. 2011). Thirdly, the social cost of air pollution is an area of concern for policymakers and economists. Effective air quality regulation requires an exact estimate of air pollution, but if pollution is overestimated, it leads to overregulation ( $\mathrm{Lu}$ et al. 2017), which ultimately affects the economic growth of a nation negatively.

The main air pollution in the atmosphere is greenhouse gases such as carbon dioxide $\left(\mathrm{CO}_{2}\right)$ (Zaidi and Saidi 2018; Apergis and Garzón 2020). Countries' regulators concerned about $\mathrm{CO}_{2}$ try to limit emissions into the air, as they are injurious to health and environmental sustainability (Fang et al. 2020). According to OECD forecasts, air pollution is "responsible for the premature mortality in the world". There are many air pollutants, but the major ones are nitrogen oxides (NOx), sulfur oxides ( $\mathrm{SOx}$ ), and carbon oxides $\left(\mathrm{CO}_{2}\right)$. These pollutants cause many diseases, especially related to respiration, not only damaging the environment but increasing healthcare expenditure.

Many factors are important to healthcare efficiency in OECD countries, broadly divided into three types: firstly, healthcare resources, both public and private, including medical technologies, physicians, pharmaceuticals, and hospital beds; secondly, socio-economic factors such as unemployment, education, income inequality, and household income; and finally, social factors concerning human interaction with the environment such as alcohol and tobacco consumption, dietary choices, and environmental pollution. Both socioeconomic and lifestyle factors are environmental variables (Varabyova and Müller 2016).

Various studies (Mărginean 2014; Murthy and Okunade 2016; Zaidi and Saidi 2018) investigate the link between healthcare expenditure and economic growth. Investment in health can boost the economy of a country, and the researchers taking this viewpoint are in favor of huge government spending on the healthcare sector (Yao et al. 2019). Another proposition, not as well developed, is that environmental degradation harms the economic growth of a country (Atilgan et al. 2017).

Apergis et al. (2017) state that the US market gives considerable importance to oil and natural gas. However, the increasing trend for renewable energy in OECD countries is decreasing the $\mathrm{CO}_{2}$ emissions in a way that promotes a healthy environment. Additional renewable energy usage is recommended as an effective approach to fighting global warming (Apergis and Payne 2010; Jebli et al. 2016; Fernando et al. 2018). Renewable energies improve public health by reducing air pollutants, promoting economic development, and creating jobs (Liu et al. 2020). In most developed countries, renewable energies are already being used as a solution to environmental pollution by reducing the use of conventional energy sources (fossil fuels). Advancement of the green economy leads to new tools related to renewable 
energy, creating new employment, while providing the solution to energy demand (Pablo-Romero et al. 2016; Moktadir et al. 2019; Rehman 2020).

Although several studies explore the importance of air pollution and healthcare expenditure, there are very few which investigate the relationships among air pollution, healthcare expenditure, and economic and noneconomic factors in OECD countries. Therefore, the present research covers this gap by conducting research in selected OECD countries into the role of renewable energy variables and various air pollutants and the role of the healthcare industry and economic growth. The study makes a threefold contribution. Firstly, the study checks the relationships between two air pollutants, COx and NOx, economic growth and healthcare spending. Secondly, the study incorporates renewable energy with healthcare and its link to growth. Thirdly, the study proposes policy implications of the use of renewable energy instead of conventional energy sources, considering the importance of public healthcare expenditure.

Wang et al. (2019) study the connections among healthcare expenditure, economic growth, and $\mathrm{CO}_{2}$ using an autoregressive distributed lag (ARDL) approach. The ARDL model provides robust findings irrespective of sample size, and provides unrestricted error correction. Khan et al. (2019) studies the relationship between investment, health, and the environment using the canonical cointegrating regression (CCR) model, which is ideal for removing second-order bias in the ordinary least squares (OLS) estimator. This paper employs the panel vector error correction model (VECM) and panel fully modified least squares (FMOLS) test, appropriate to the study, to identify the association and trend of the relationships among the variables in the model. The VECM is used to examine the path of causation. It limits the long-run behavior of the endogenous variables unless they converge and provide shortrun correction dynamics. FMOLS, introduced by Hansen and Phillips in 1990, is used to check the robustness of results, as it is ideal for a small amount of data. This method is ideal for achieving asymptotic efficiency by modifying the least squares and is used to estimate the association among the variables (Kalim and Shahbaz 2009). The study reveals that there is a relationship between air pollution and healthcare expenditure and that the use of renewable energy has a substantial effect on healthcare spending that triggers economic growth. Noneconomic factors play an important role in healthcare spending.

The paper is organized as follows: a review of the literature related to the impacts of air pollution, economic and noneconomic factors, and renewable energy on healthcare expenditure is given in the "Literature review" section; the "Data and methodology" section describes the data and methodology; the "Results and discussion" section provides the results, and discussion; and the "Conclusion and policy implications" section contains the conclusion and policy implications.

\section{Literature review}

There are two research strands in the current literature review. The first covers the effects of air pollution, economic and noneconomic factors, and renewable energy on healthcare expenditure. A table is provided that contains a summary of the literature in the second strand (Table 1).

\section{Air pollution and healthcare expenditure}

Environmental pollution interests many economists and researchers. Air pollution is one of the core elements of the environment, and if air pollution is increased, it affects human health by affecting the metabolism. A wide strand of literature (Murthy and Okunade 2016; Chaabouni and Saidi 2017; Li et al. 2019) examines the connection between healthcare and air pollution. Yazdi and Khanalizadeh (2017) conduct a study exploring the major determinants of healthcare expenditure. The study uses economic and environmental quality variables, and takes data from the MENA region from 1995 to 2014. The ARDL model is used to reveal that emissions of carbon and particulates between 2.5 and $10 \mu \mathrm{m}$ (PM10) have a significant and direct connection with healthcare expenditure. This means that when these gas emissions increase, healthcare expenditure also increases. Income is shown to have no relationship to healthcare expenditure. Other studies show similar results that high air pollution increases the mortality rate and there is a positive relationship between mortality and air pollution (Tran et al. 2018; Wang et al. 2020).

Chaabouni and Saidi (2017) inspect the nature of the connections among $\mathrm{CO}_{2}$ emissions, GDP and healthcare. The data comes from 51 countries over the period 1995-2013. The countries are split into 3 groups according to income. The study uses a Gaussian mixture model (GMM) and dynamic simultaneous-equations models for analysis. The results show that bidirectional connectedness is present between carbon discharge and GDP, and GDP and healthcare spending. Moreover, a unidirectional connection exists from $\mathrm{CO}_{2}$ emissions to healthcare spending in most countries, except low-income countries.

Saidi and Hammami (2016) find that environmental problems are mainly the result of high $\mathrm{CO}_{2}$ discharge, which has an adverse effect on human health. The study is conducted in the African region from 1990 to 2015, and uses the ARDL model for analysis. The results show a positive association between economic growth and healthcare expenditure but a significant negative relationship between carbon emissions 
Table 1 Summary of the literature reviewed

\begin{tabular}{|c|c|c|c|c|}
\hline Wang et al. (2019) & Pakistan & 1995-2017 & $\begin{array}{l}\text { This paper examines the dynamic effect } \\
\text { of carbon emissions, healthcare spending } \\
\text { and economic growth using ARDL. }\end{array}$ & $\begin{array}{l}\mathrm{HE} \leftrightarrow \mathrm{CO} 2 \\
\mathrm{HE} \leftrightarrow \mathrm{EG} \\
\mathrm{CO} 2 \leftrightarrow \mathrm{EG} \\
\mathrm{FCAP} \leftrightarrow \mathrm{EG}\end{array}$ \\
\hline Yao et al. (2019) & China & $2001-2016$ & $\begin{array}{l}\text { This paper examines the association between } \\
\text { healthcare spending and education using } \\
\text { quantitative and qualitative measures of } \\
\text { education. }\end{array}$ & $\begin{array}{l}\text { HE no relation with } \\
\text { education quantity } \\
\text { EDUQUL } \uparrow \mathrm{HE} \uparrow\end{array}$ \\
\hline Azam et al. (2019) & China & $1995-2016$ & $\begin{array}{l}\text { In this paper, canonical correlation regression } \\
\text { is employed to study the associations among } \\
\text { environment, investment, and healthcare } \\
\text { expenditure. }\end{array}$ & $\begin{array}{l}\mathrm{ENG} \uparrow \mathrm{FDI} \uparrow \\
\mathrm{ENG} \uparrow \mathrm{ENV} \uparrow \\
\mathrm{ENG} \uparrow \mathrm{HE} \uparrow\end{array}$ \\
\hline Blázquez-Fernández et al. (2019) & 29 OECD countries & 1995-2014 & $\begin{array}{l}\text { This paper investigates the relationship between } \\
\text { environmental pollution and expenditure } \\
\text { related to healthcare. }\end{array}$ & $\begin{array}{l}\mathrm{SO} 2 \uparrow \mathrm{HEC} \downarrow \\
\mathrm{INC} \uparrow \mathrm{HEC} \uparrow\end{array}$ \\
\hline Li et al. (2019) & 31 cities in China & 2013-2016 & $\begin{array}{l}\text { This study examines the economic effect of } \\
\text { environmental pollution }\left(\mathrm{SO}_{2}, \mathrm{CO}_{2}\right) \text { on } \\
\text { health expenditure using two stage DEA } \\
\text { methods. }\end{array}$ & $\begin{array}{l}\mathrm{GDP} \uparrow \mathrm{HE} \uparrow \\
\mathrm{SO} 2 \uparrow \mathrm{HE} \uparrow \\
\mathrm{CO} 2 \uparrow \mathrm{HE} \uparrow\end{array}$ \\
\hline Ye and Zhang (2018) & $\begin{array}{l}\text { OECD and five } \\
\text { other developing } \\
\text { countries. }\end{array}$ & 1995-2015 & $\begin{array}{l}\text { This paper analyses the association between } \\
\text { healthcare and economic growth. }\end{array}$ & $\mathrm{EG} \leftrightarrow \mathrm{HCE}$ \\
\hline Wang et al. (2018) & 22 countries & 2004-2013 & $\begin{array}{l}\text { This study examines the impact of shocks in } \\
\text { healthcare expenditure, economic growth } \\
\text { and life insurance consumption. }\end{array}$ & $\begin{array}{l}\mathrm{PH} \uparrow \mathrm{EG} \uparrow \\
\mathrm{PH} \uparrow \mathrm{INCG} \uparrow \\
\mathrm{PH} \uparrow \mathrm{HCE} \uparrow\end{array}$ \\
\hline Chaabouni and Saidi (2017) & 51 countries & 1995-2013 & $\begin{array}{l}\text { This study checks the associations between } \\
\text { expenditure related to health, economic } \\
\text { growth and air pollutants employing } \\
\text { GMM. }\end{array}$ & $\begin{array}{l}\mathrm{CO} 2 \leftrightarrow \mathrm{GDP} \\
\mathrm{EF} \leftrightarrow \mathrm{HCE} \\
\mathrm{CO} 2 \leftrightarrow \mathrm{HE}\end{array}$ \\
\hline Atilgan et al. (2017) & Turkey & $1975-2013$ & $\begin{array}{l}\text { This study examines the dynamic correlation } \\
\text { between economic growth and healthcare } \\
\text { spending using the ARDL method. }\end{array}$ & $\mathrm{EG} \uparrow \mathrm{HEC} \uparrow$ \\
\hline Murthy and Okunade (2016) & US & $1960-2012$ & $\begin{array}{l}\text { This study analyses the major drivers of } \\
\text { healthcare expenditure using the ARDL } \\
\text { approach. }\end{array}$ & $\begin{array}{l}\text { INC } \Omega \text { AGE } \\
\mathrm{AGE} \Omega \mathrm{HCE} \\
\mathrm{INC} \uparrow \mathrm{HCE} \uparrow \\
\mathrm{AGE} \uparrow \mathrm{HEC} \uparrow \\
\mathrm{HRD} \uparrow \mathrm{HCE} \uparrow\end{array}$ \\
\hline Omri et al. (2014) & 54 countries & $1990-2011$ & $\begin{array}{l}\text { This paper investigates the dynamic } \\
\text { relationships among economic growth, } \\
\mathrm{CO}_{2} \text { emissions and FDI. }\end{array}$ & $\begin{array}{l}\mathrm{FDI} \leftrightarrow \mathrm{EG} \\
\mathrm{FDI} \leftrightarrow \mathrm{CO} 2 \\
\mathrm{CO} 2 \leftrightarrow \mathrm{EG}\end{array}$ \\
\hline Baltagi and Moscone (2010) & 20 OECD countries & 1971-2004 & $\begin{array}{l}\text { This study examines the role of income } \\
\text { (GDP) on healthcare expenditure. }\end{array}$ & INC $\uparrow \mathrm{HEC} \downarrow$ \\
\hline Gövdeli (2019) & 26 OECD countries & $1992-2014$ & $\begin{array}{l}\text { This study investigates the correlation } \\
\text { between health expenditure, economic } \\
\text { growth, and } \mathrm{CO}_{2} \text { emissions. }\end{array}$ & $\begin{array}{l}\mathrm{GDP} \uparrow \mathrm{HE} \uparrow \\
\mathrm{CO} 2 \leftrightarrow \mathrm{HE} \\
\mathrm{GDP} \leftrightarrow \mathrm{CO} 2\end{array}$ \\
\hline Apergis et al. $(2018 \mathrm{a}, \mathrm{b})$ & 42 African countries & 1995-2011 & $\begin{array}{l}\text { This study investigates the relationships } \\
\text { between renewable energy, healthcare, } \\
\text { and GDP. }\end{array}$ & $\begin{array}{l}\mathrm{RNE} \leftrightarrow \mathrm{CO} 2 \\
\mathrm{RNE} \uparrow \mathrm{HE} \uparrow\end{array}$ \\
\hline
\end{tabular}

and healthcare expenditure. Some studies (Usman et al. 2019; Chaabouni and Saidi 2017) show similar results, proving that high air pollution increases the mortality rate, and it has a negative relationship with carbon emission or air pollution.

\section{Economic growth and healthcare expenditure}

Healthcare expenditure differs across the world, and health is usually considered a means for increasing the economic growth of a country. There are two schools of thought regarding the link between healthcare spending and economic growth. According to the first (Omri et al. 2014; Ye and Zhang 2018; Usman et al. 2019), if a country is able to maintain a healthy lifestyle by spending more on healthcare, then the social welfare and life expectancy ratio of the average person is increased. In other words, if the health condition of workers is increased, then these healthy workers can work more efficiently and produce more effective outputs. The result of efficiency is that labor productivity is increased. These conditions cause a rise in the income of the country and 
economic development is enhanced. On the other hand, some researchers (Atilgan et al. 2017; Lee et al. 2019) hold that economic growth and healthcare spending have a two-way relationship. High healthcare expenditure leads to high economic growth, and if a country has a high GDP ratio, they can spend more on healthcare, while poor countries with a low GDP ratio cannot spend as much on healthcare, eventually making the country poorer.

Different studies show different relationships between healthcare spending and economic growth. Wang et al. (2019) explore a dynamic type of association in Pakistan using annual data over the period 1995 to 2017, using Granger causality and ARDL models to extract results from the data. The paper reveals that both short-run and long-run associations are present between most of the variables $\left(\mathrm{CO}_{2}\right.$, healthcare spending, and economic growth). The Granger causality proves that bidirectional causality exists between carbon emissions and healthcare expenditure. The result proves a bidirectional causal relationship between carbon emissions and growth, and economic growth and grossfixed capital formation.

Omri et al. (2014) conduct a study investigating stationarity and cointegration across variables including economic growth (GDP) and healthcare spending across 13 MENA region countries over the period 1995 to 2005. Unit root test findings reveal that nonstationarity exists between healthcare spending and economic growth (GDP). The study reveals that healthcare expenditure and economic growth are integrated, showing that there is an inverse relationship between healthcare expenditure and gross domestic product, and that healthcare spending is a necessity in the countries sampled.

A few studies use foreign direct investment as proxy for economic growth and explore its relationship with healthcare expenditure. Usman et al. (2019) study the effect of air pollution, and economic, and noneconomic and social factors on healthcare expenditure. The proxy for air pollution is $\mathrm{CO}_{2}$ emissions, the economic factors include GDP and FDI, and the noneconomic factors include education and population age. Healthcare expenditure has two elements, government expenditure and private expenditure. The study takes data from 13 emerging nations for the period 1994 to 2017. The research uses panel cointegration linear model bootstrapping to analyze the data. Most of the factors (carbon emissions, GDP, environment index, FDI, and education) are significantly related to healthcare spending (public and private). The study results reveal that air pollution $\left(\mathrm{CO}_{2}\right.$ emissions) and the environment index are significantly positively associated with public healthcare spending, but both measures have a significant negative relationship with private healthcare expenditure. The GDP growth ratio is positively associated with both healthcare expenditures (private and government).

One noneconomic factor, having an ageing population, has a significant positive connection with both proxies of healthcare spending, while education has a negative relationship with private healthcare expenditure. Some other studies (Mehrara et al. 2011; Atilgan et al. 2017; Yao et al. 2019) find that GDP and healthcare spending are positively and significantly related. Most early research studies have inconclusive results about the association between healthcare spending and economic growth. Moreover, most studies use GDP as a proxy for economic growth; current GDP and foreign direct investment (FDI) are very rarely used as proxies for economic growth in the literature, and the current study fills this gap.

\section{Noneconomic factors and healthcare expenditure}

Noneconomic factors affecting healthcare expenditure are rarely explored, and the current study addresses this issue. Yao et al. (2019) study social factors such as education and their connection with healthcare spending. The study takes data from China over the period 2001 to 2016, using the generalized method of moments (GMM) to mitigate the impact of endogeneity in the variables of the study. The study concludes that quantity of education has no relationship with healthcare spending, but healthcare spending is positively and significantly related to education quality.

Research conducted by Mehrara et al. (2011) examines the nature and type of relationship between education, human wellbeing indicators, and healthcare expenditure in Asia and Africa. The sample period is 1998 to 2007, and a graphical method and regression analysis are employed to investigate the data. The study concludes that education is significantly positively related to healthcare expenditure. In other words, when education expenditure increases healthcare spending also increases. Some other studies such as Li et al. (2019) and Kais and Sami (2016) show that that there is a negative relationship between education and healthcare expenditure, while one study shows no important connection between education and healthcare expenditure. There are very rare studies (Wang et al. 2018; Usman et al. 2019) which investigate the relationship between noneconomic factors and healthcare expenditure. The current study fills this gap by using a noneconomic factor, education, to examine the association with healthcare.

\section{Renewable energy and healthcare expenditure}

There has been a rapid increase in renewable energy sources used for heating, cooling, transportation, and electricity generation. Renewable energy is a substitute for conventional energy which not only benefits the environment but also promotes the economy by enhancing production and reducing healthcare expenditure. Khan et al. (2019) investigates the links between healthcare expenditure, renewable energy consumption, and some indices of logistics performance in selected ASEAN countries from 2007 to 2017. According to the author, healthcare expenditure decreases and 
labor productivity improves by using green energy. The use of renewable energy in logistic operations leads to a decrease in air pollutants, especially greenhouse gases, and improved health. This leads to an increase in economic growth by promoting efficiency among laborers. The more emphasis there is on environmental performance more it promotes investment.

Apergis et al. (2018a, b) study the relationships between renewable energy, healthcare, and GDP in 42 African countries from 1995 to 2011. They find short-run bidirectional causality between renewable energy and $\mathrm{CO}_{2}$ emissions, and a long-run unidirectional relationship between renewable energy and healthcare. Similar results are drawn by (Apergis and Payne 2009; Alola et al. 2019).

Jebli's (2016) study of Tunisia concludes that there is bidirectional long-run causality between health status and combustible renewable waste consumption. This result implies a possible correlation between health and renewable energy. Air pollution significantly burdens people economically, by increasing healthcare expenditure and decreasing the labor productivity. So, renewable energy is a solution to the problem of improving health conditions and promoting savings (Buonocore et al. 2016).

From the above discussion, it is understood that use of renewable energy decreases air pollutant emissions, meaning less health problems and therefore less healthcare expenditure.

\section{Data and methodology}

This research uses annual panel data from 28 OECD countries, from 2002 to 2018, obtained from the official website of the OECD and Bloomberg. The study takes healthcare expenditure (HEALTH) as a dependent variable, and GDP is used as a proxy for economic growth. $\mathrm{CO}_{2}$ and $\mathrm{NOx}$ are taken as proxies for air pollutants. Education (EDU) and renewable energy (RNE) are independent variables.

\section{Unit root test}

For the classical regression model, both dependent and independent variables need to be stationary, meaning they should have zero mean and finite variance. Stationarity is a state in which the regressor parameters (mean and standard deviation) do not change over time. The fundamental objective of employing a cointegration structure is to investigate whether the variables under study have a long-run relation. At level, they are nonstationary, and at first difference, they become stationary. Granger and Newbold (1986) state that if the data is a time series and are nonstationary at that time, the findings of the regression model are false. Hence the first thing to do, before using any suitable model, is to check whether the dataset fulfils the condition of stationarity. The data stationarity can be tested using the augmented Dickey Fuller technique.
The augmented Dickey Fuller technique is used in the panel data for the unit root test, and it is specified as:

$$
\begin{aligned}
\Delta X_{\mathrm{it}}= & \alpha_{0}+\delta X_{\mathrm{it}-1}+\beta_{1} \Delta X_{\mathrm{it}-1}+\beta_{2} \Delta X_{\mathrm{it}-2}+\ldots \\
& +\beta_{\mathrm{p}} \Delta X_{\mathrm{it}-\mathrm{p}}+u_{\mathrm{it}}
\end{aligned}
$$

where $X_{\text {it }}$ represents the component of time series, $\alpha_{0}$ denotes the intercept term, the coefficient having unit root is given by $\delta$, the first difference augmented lag parameters of Zitl are denoted by $\beta_{1}$ to $\beta_{\mathrm{p}}$ which represent the autoregressive process with $p$ th order, and the error term is represented by $u_{\mathrm{it}}$.

\section{Cointegration test}

When we conclude that the variable under study is stationary at first difference, the next step is to explore the nature of the long-run associations among the variables. In this study, we employ the two panel cointegration test, which includes the Kao and Pedroni tests. These two tests are extensions of the Engle Granger two step cointegration test. In the Pedroni approach, we have to test whether the null hypothesis $\mathrm{pi}=1$. In the Pedroni test, we make two alternative hypotheses, one homogenous the other heterogeneous; both deal with $\mathrm{pi}<1$ for all $i$. The homogenous alternative is for the panel test, while the heterogeneous alternative is for the group test. In the homogenous alternative, the common autoregressive coefficient is applied to a cross section, while for the group test, for each cross section an individual autoregressive coefficient is applied. In the heterogeneous alternative, there is more chance of heterogeneity because it does not require a common value of $r$.

For a robustness check, the Kao cointegration test is used. In this approach, in first stage of estimation, we use the cross section specific intercepts and homogenous coefficients on the regressor. This method endorses the cointegration in the data.

\section{Vector autoregression}

The analysis starts by authorizing an $n$-factor vector $x_{i t}$ that has $p$ th order, using an autoregressive Gaussian method:

$$
\begin{aligned}
& p \\
& x_{\mathrm{it}}=\mu+\sum \psi_{i} x_{\mathrm{it}-1}+\varepsilon_{\mathrm{it}} \text { where } t=1,2,3, \ldots, N \text { and } i=1,2,3, \ldots, K
\end{aligned}
$$$$
i=1
$$

The vector constant is given by $\mu, \varepsilon_{\mathrm{i}}$ represents a normal and independent distribution of $n$ facets having zero mean and covariance $\Omega$ with a nonsingular matrix, and $x_{\mathrm{t}}$ denotes the endogenous factor vector. The above equation can be reexamined through the error correction model (ECM):

$$
\begin{aligned}
& P-1 \\
& \Delta x_{i t}=\mu+\sum \varphi_{i} \Delta x_{i t-1}-\varphi_{0} x_{i t-1}+\varepsilon_{i t} \\
& i=1
\end{aligned}
$$


where $\varphi_{0}=I-\left(\psi_{1}+\psi_{2}+\ldots+\psi_{p}\right)$ and $\varphi_{\mathrm{i}}=-\sum \psi_{j}$, and $i=1$, $2,3 \ldots M$.

Here matrix $\psi(n \times n)$ is equal to $\varphi_{0}$, showing the linear setup in $x_{t}$ which validates the condition of stationarity.

\section{Vector error correction model}

In order to check the long-run association between the variables and the cointegrated sequence among the variables, the vector error correction model (VECM) is used. VECM is employed to recognize the quantity of cointegrating vectors in a model. When two nonstationary variables are linearly independent, this shows that they are ranked of two.

In ECM, coefficients with negative sign show short-term variations between the independent and the dependent variables and further elaborate the long-term association among variables. VECM has the feature of restricting the endogenous variables in long term until they achieve convergence. Steady long-term association occurs in the variables, when there is negative sign with significant variable. This shows that only short-run fluctuation appears between the two variables. The
VECM allows short-run modification of endogenous variables.

The error correction term (ECT) is a cointegration term. The ECT shows how partial short-run adjustment is used for correction in long-run equilibrium. So, VECM is employed to spot short- and long-run associations between variables. In cases where variables are not cointegrated, the panel vector autoregressive (VAR) approach is suitable.

\section{Panel FMOLS}

Being asymptotically biased is a key characteristic of ordinary least squares (OLS). These estimator distributions rely upon nuisance parameters. Undesirable endogeneity and serial correlation are properties of nuisance parameters.

To address this issue, panel FMOLS provide optimum cointegration regression estimates. Hansen and Phillips (1990) establish a fully modified OLS, or FMOLS, regression model. FMOLS methodology is employed to tackle endogeneity and autocorrelation problems in regression models that are the outcome of the existence of cointegrated variables. Consider a time series $(n+1)$ dimensional vector

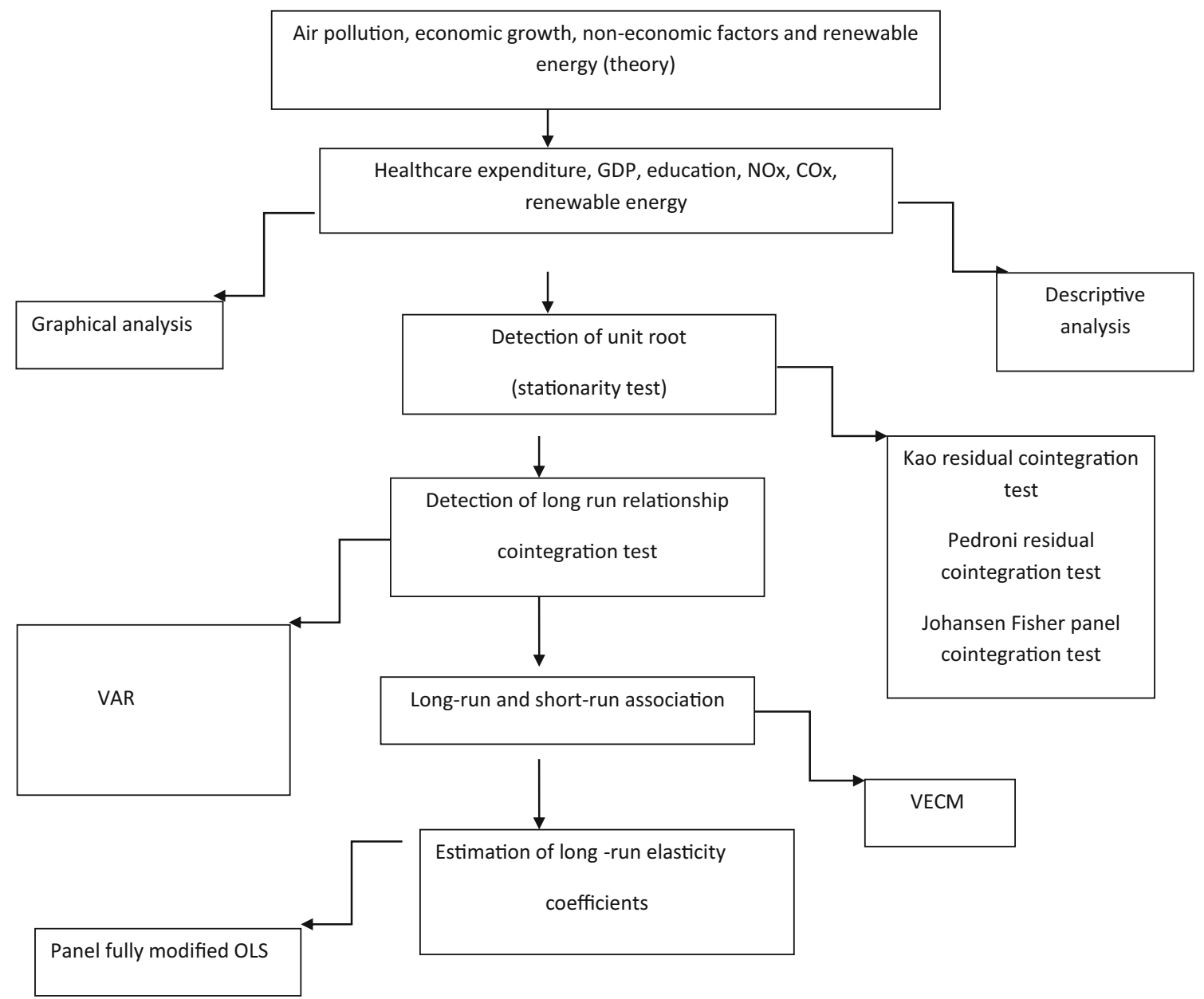

Fig. 4 Flow diagram of methodology 
Table 2 Descriptive statistics

\begin{tabular}{lllllll}
\hline & HEALTH & GDP & EDU & NOX & $\mathrm{CO}_{2}$ & \multicolumn{2}{l}{$\mathrm{RNE}$} \\
\hline Mean & 0.905020 & 5.622078 & 1.357175 & 2.488853 & 1.972466 & 3.650658 \\
Median & 0.913628 & 5.541585 & 1.324681 & 2.346433 & 1.828337 & 3.706511 \\
Maximum & 1.240000 & 7.380000 & 1.901795 & 4.335103 & 3.758147 & 5.215108 \\
Minimum & 0.601951 & 3.921934 & 0.816729 & 1.210000 & 0.278754 & 1.580012 \\
Standard Dev & 0.110842 & 0.654286 & 0.249480 & 0.640747 & 0.693643 & 0.624507 \\
Skewness & -0.029255 & -0.083669 & 0.242351 & 0.409264 & 0.079395 & -0.302211 \\
Kurtosis & 3.122637 & 2.936235 & 2.350445 & 2.690875 & 2.980342 & 3.356952 \\
\hline
\end{tabular}

$\left(R_{t}, Y_{t}^{\prime}\right)$ with a cointegration model:

$R_{t}=\beta Y_{t}^{\prime}+\delta X_{t}^{\prime}+U_{1 t}$

where $X_{t}^{\prime}=\left(X_{1 t}^{\prime}, X_{2 t}^{\prime}\right)^{\prime}$ is the deterministic regression trend, the stochastic repressor is represented by $Y_{t}^{\prime}$ which is administered by the system equation method, and $U_{1 t}$ is the residual estimate.

The methodological workflow is shown in Fig. 4.

\section{Results and discussion}

In this part, we provide the empirical evidence for how air pollution, renewable energy, and expenditure on healthcare and GDP in the OECD nations are interlinked. To analyze the dataset, firstly we apply descriptive statistics to explore the data in its present form, followed by the panel unit root test, panel cointegration, panel FMOLS, and panel VECM. The descriptive statistics, given in Table 2 , show that the GDP has the highest mean, while health expenditure has the lowest mean value and volatility. $\mathrm{CO}_{2}$ emission has a mean value of 1.972, which shows high deviation from the mean value. GDP and renewable energy are negatively skewed, whereas GDP has the highest maximum value. Most of the variables are negatively skewed and leptokurtic.

The output of the panel unit root test for individual variables is presented in Table 3 The null hypothesis is that there is unit root for all variables in the study. For the panel unit test,

Table 3 Panel unit root test at level and first difference

\begin{tabular}{lll}
\hline Variable & Level & First difference \\
\hline $\mathrm{D}\left(\mathrm{CO}_{2}\right)$ & $-7.898(0.000)$ & $-5.542(0.000)$ \\
EDU & $-3.677(0.000)$ & $2.076(0.981)$ \\
GDP & $4.143(1.000)$ & $-4.260(0.000)$ \\
HEALTH & $1.263(0.896)$ & $-2.102(0.017)$ \\
D (NOX) & $-5.945(0.000)$ & $-5.015(0.000)$ \\
RNE & $4.505(1.000)$ & $-2.173(0.014)$ \\
\hline
\end{tabular}

each variable under study has a unit root under the null hypothesis. At a 5\% level of significance, we do not reject the null hypothesis for most variables. The results show that most of the variables are stationary at first difference, so the null hypothesis is rejected at a $5 \%$ level of significance.

Table 4 shows the results of panel cointegration, tested by three methods: the Kao, Pedroni, and Johansen Fisher cointegration tests. In the Pedroni cointegration test, there is no association between the variables under study, confirming the null hypothesis. At the 5\% and $1 \%$ level of significance, there is cointegration among the variables, so the null hypothesis is rejected. The Johansen Fisher panel test is used to check whether the variables under study have any association in the long run. The null hypothesis is that there is no cointegration among the variables. At the 5\% and $1 \%$ levels of significance, the null hypothesis is rejected, which means there is cointegration in the data. So, in the panel data there is a long-run association.

The result of the panel VECM reported in Table 5 show the long-run association between the variables. The VAR lag shows how many lags should be taken in the model, and in order to select the lag-length, AIC, SIC, and HQ are used as

Table 4 Results of cointegration tests

\begin{tabular}{lll}
\hline Hypothesized & Fisher stat.* & Fisher stat.* \\
\hline No. of CE(s) & (Trace test) & (Max-Eigen test) \\
None & $49.91(0.978)$ & $49.91(0.978)$ \\
At most 1 & $134.1(0.000)$ & $373.6(0.000)$ \\
At most 2 & $627.7(0.000)$ & $646.1(0.000)$ \\
At most 3 & $659.2(0.000)$ & $457.6(0.000)$ \\
At most 4 & $346.8(0.000)$ & $251.8(0.000)$ \\
At most 5 & $249.0(0.000)$ & $249.0(0.000)$ \\
Pedroni (Engle-Granger based) test individual intercept \\
Panel v-statistic & & $-0.869(0.807)$ \\
Panel rho-statistic & & $4.511(1.000)$ \\
Panel PP-statistic & & $-1.698(0.044)$ \\
Panel ADF-statistic & & $-2.454(0.007)$ \\
\hline
\end{tabular}

() shows $p$ value for trace test and max-Eigen test 
Table 5 Panel VECM

\begin{tabular}{|c|c|c|c|c|c|c|}
\hline Error correction: & D(HEALTH) & $\mathrm{D}(\mathrm{GDP})$ & $\mathrm{D}(\mathrm{EDU})$ & $\mathrm{D}(\mathrm{NOX})$ & $\mathrm{D}(\mathrm{CO} 2)$ & $\mathrm{D}(\mathrm{RNE})$ \\
\hline \multirow[t]{2}{*}{ CointEq1 } & -0.001688 & 0.004650 & -0.013914 & -0.030304 & -0.005183 & 0.052725 \\
\hline & {$[-0.42759]$} & [0.25239] & {$[-1.56908]$} & {$[-3.13086]$} & {$[-1.09711]$} & [6.47761] \\
\hline \multirow[t]{2}{*}{ D(HEALTH(- 1)) } & 0.111071 & -0.113520 & 0.059676 & 0.045967 & 0.099361 & -0.085750 \\
\hline & {$[2.56764]$} & {$[-0.56222]$} & {$[0.61400]$} & [0.43329] & [1.91882] & {$[-0.96116]$} \\
\hline \multirow[t]{2}{*}{$\mathrm{D}(\mathrm{GDP}(-1))$} & -0.010540 & 0.011298 & -0.024899 & -0.012325 & -0.015361 & 0.022534 \\
\hline & {$[-1.12259]$} & {$[0.25778]$} & {$[-1.18030]$} & {$[-0.53526]$} & {$[-1.36665]$} & [1.16369] \\
\hline \multirow{2}{*}{$\mathrm{D}(\mathrm{EDU}(-1))$} & -0.028374 & 0.009151 & -0.023924 & -0.016049 & 0.000722 & 0.090672 \\
\hline & {$[-1.49874]$} & {$[0.10355]$} & {$[-0.56244]$} & {$[-0.34565]$} & {$[0.03188]$} & [2.32227] \\
\hline \multirow[t]{2}{*}{$\mathrm{D}(\operatorname{NOX}(-1))$} & -0.036317 & 0.138044 & -0.052213 & 0.165543 & 0.120703 & -0.016675 \\
\hline & {$[-1.06778]$} & {$[0.86953]$} & {$[-0.68325]$} & [1.98461] & [2.96460] & {$[-0.23771]$} \\
\hline \multirow[t]{2}{*}{$\mathrm{D}\left(\mathrm{CO}_{2}(-1)\right)$} & 0.087953 & -0.106227 & 0.074302 & 0.051724 & -0.146754 & -0.059360 \\
\hline & [2.04113] & {$[-0.52815]$} & {$[0.76747]$} & {$[0.48946]$} & {$[-2.84507]$} & {$[-0.66796]$} \\
\hline \multirow[t]{2}{*}{$\mathrm{D}(\mathrm{RNE}(-1))$} & -0.108964 & 0.082315 & -0.073163 & -0.039813 & -0.028150 & -0.006315 \\
\hline & {$[2.45443]$} & [0.89402] & {$[-1.65081]$} & {$[-0.82298]$} & {$[-1.19216]$} & {$[-0.15523]$} \\
\hline \multirow[t]{2}{*}{$\mathrm{C}$} & 0.004955 & 0.016429 & -0.009039 & -0.007873 & 0.001047 & 0.021316 \\
\hline & $(0.00103)$ & $(0.00481)$ & $(0.00232)$ & $(0.00253)$ & $(0.00123)$ & $(0.00213)$ \\
\hline
\end{tabular}

*significant at $1 \%$; * significant at $5 \%$; ***significant at $10 \%$

criteria; in all three cases, lower values are better. All show significance at lag 1 having the lowest value. These criteria show that, for the panel vector error correction model, the lag length should be 1 . The equation shows that long-term association is evident among the variables. Public healthcare expenditure has a long-run association with renewable energy sources, a result which is consistent with Buonocore et al. (2016), which implies that when governments make investments in renewable energy products it helps overcome environmental effects which reduces the stress on public health expenditure. In contrast, air pollution puts a significant burden on the economic cost for people, by increasing their healthcare expenditure and decreasing labor productivity. Renewable energy improves health conditions and promotes savings. In addition, the results show that the lag value of $\mathrm{CO}_{2}$ has a positive association with public health expenditure. This means that an increase in air pollutants causes a rise in diseases, which requires more healthcare attention, and therefore, a polluted environment requires an increase in healthcare expenditure. Our results are consistent with Khoshnevis Yazdi and Khanalizadeh (2017) that an increase in gas emissions causes a rise in healthcare expenditure. The air pollutant NOx is significantly positively related to $\mathrm{CO}_{2}$. This means that they are complementary to each other (anything that produces $\mathrm{CO}_{2}$ also produces a considerable amount of NOx). Moreover, education is positively and significantly related to renewable energy consumption. As the education of people increases, they gain awareness of the environment and prefer to use renewable energy resources to reduce pollution (Özçiçek and Ağpak 2017).
Table 6 shows the outcome of the panel FMOLS. The values of adjusted $R$ and $R$ squared are 89.31 and 90.01, respectively. This shows that nearly $89 \%$ of the deviation in public healthcare expenditure of OECD economies is described by the explanatory variables. GDP as proxy of economic growth is significantly positively connected to public healthcare spending of OECD economies, which is supported by Gövdeli (2019). This shows that economic activity in advanced economies leads to a rise in public healthcare spending, as a response to increasing health issues associated with toxic air pollutants caused by industry. However, we see that increasing education can help reduce public health expenditure, which is interpreted as the more educated the people in a society are, the more they will be conscious about their health

Table 6 Result of panel fully modified least squares

\begin{tabular}{lllll}
\hline Variable & Coefficient & Std. error & $t$ statistic & Prob. \\
\hline GDP & 0.021745 & 0.016552 & 2.313737 & $0.019 * *$ \\
EDU & -0.081747 & 0.031555 & -2.590617 & $0.009 * * *$ \\
NOX & 0.071932 & 0.031188 & -2.306377 & $0.021^{* *}$ \\
$\mathrm{CO}_{2}$ & 0.074012 & 0.061887 & 2.195907 & $0.032 * *$ \\
$\mathrm{RNE}$ & -0.091674 & 0.021708 & 4.223076 & $0.00^{* * *}$ \\
$R$ squared & 0.900167 & Mean dependent Var & 0.908631 \\
Adjusted $R$ squared & 0.893149 & SD dependent Var & 0.110125 \\
SE of regression & 0.035998 & Sum squared resid & 0.737330 \\
Long-run variance & 0.002626 & & & \\
\hline
\end{tabular}

$*$ significant at $1 \% ; * *$ significant at $5 \% ; * * *$ significant at $10 \%$ 
(Li et al. 2019; Kais and Sami 2016). Furthermore, it is evident that air pollutants such as NOx and carbon emissions $\left(\mathrm{CO}_{2}\right)$ have a significant influence on the public healthcare spending of OECD economies. Finally, renewable energy and healthcare spending are significantly related, because the use of renewable energy improves the environment and reduces toxic pollution in the air, which causes less damage to the health of people. These results are supported by Apergis et al. $(2018 \mathrm{a}, \mathrm{b})$, who prove that healthcare and renewable energy have a unidirectional relationship.

\section{Conclusion and policy implications}

This paper emphasizes the relationships between air pollutants, economic growth, and public health in selected OECD economies. There is limited literature available related to air pollution, healthcare spending and economic growth in these countries. We also consider renewable energy, and its effect on healthcare expenditure and economic growth. This study uses annual data from 2002 to 2018, and employs panel FMOLS and VECM. Firstly, the panel unit root test for individual variables is employed to check for stationarity. Secondly, the panel cointegration test is employed to find the associations among the variables under study, followed by the panel VECM, which is applied to check for long-run associations between the variables, and the results show that there are such associations. Renewable energy has a significant long-run relationship with healthcare expenditure, which signifies that air pollution deteriorates health. To reduce the damage to health, the only solution is to replace conventional energy sources with renewable sources.

Lastly, using panel FMOLS, we check how the dependent and independent variables are related. It is shown that healthcare spending and air pollutants $\left(\mathrm{CO}_{2}\right)$ are significantly and positively related, which indicates that air pollution adversely affects the health sector. The study concludes that renewable energy is a solution to problems associated with health expenses, which can be achieved by improving the environmental conditions for health and promoting labor productivity. The results show that investment in renewable energy resources leads to environmental sustainability, reduces the use of conventional energy sources, and promotes health and other noneconomic factors like education.

The policy implications are that a reduction in air pollution can be achieved by replacing conventional energy sources with renewable energy sources. Governments should play a role in this regard by compelling stakeholders to use less polluting energy resources. This can be done by imposing taxes on air polluting firms, which would eventually reduce air pollution in the environment and reduce healthcare expenditure. The findings of this study provide direction for policy makers, showing how pollution reducing policies improve economic growth by improving the health of people by reducing air pollution-related diseases.

Authors' contributions GMK conceptualized the idea, did the analysis, and wrote the initial draft. SJHS reviewed and proof read, and also supervised the work.

Data availability The date used in this study is available on the official website of the OECD and Bloomberg.

\section{Compliance with ethical standards}

Ethical approval Not applicable.

Consent to participate Not applicable.

Consent for publication Not applicable.

Competing interests The authors declare that they have no competing interests.

\section{References}

Akca N, Sonmez S, Yilmaz A (2017) Determinants of health expenditure in OECD countries: a decision tree model. Pakistan J Med Sci 33(6): 1490-1494

Alola AA, Bekun FV, Sarkodie SA (2019) Dynamic impact of trade policy, economic growth, fertility rate, renewable and nonrenewable energy consumption on ecological footprint in Europe. Sci Total Environ 685:702-709

Apergis N, Chang T, Christou C, Gupta R (2017) Convergence of health care expenditures across the US States: A reconsideration. Soc Indic Res 133(1):303-316

Apergis N, Garzón AJ (2020) Greenhouse gas emissions convergence in Spain: evidence from the club clustering approach. Environ Sci Pollut Res:1-5

Apergis N, Payne JE (2009) CO2 emissions, energy usage, and output in Central America. Energy Policy 37(8):3282-3286

Apergis N, Payne JE (2010) Renewable energy consumption and economic growth: evidence from a panel of OECD countries. Energy Policy 38(1):656-660

Apergis N, Cooray A, Rehman MU (2018a) Do energy prices affect US investor sentiment? J Behav Financ 19(2):125-140

Apergis N, Jebli MB, Youssef SB (2018b) Does renewable energy consumption and health expenditures decrease carbon dioxide emissions? Evidence for sub-Saharan Africa countries. Renew Energy 127:1011-1016

Apergis N, Bhattacharya M, Hadhri W (2020) Health care expenditure and environmental pollution: a cross-country comparison across different income groups. Environ Sci Pollut Res 27(8):8142-8156

Atilgan E, Kilic D, Ertugrul HM (2017) The dynamic relationship between health expenditure and economic growth: is the health-led growth hypothesis valid for Turkey? Eur J Health Econ 18(5): 567-574

Azam M, Khan AQ, Ozturk I (2019) The effects of energy on investment, human health, environment and economic growth: empirical evidence from China. Environ Sci Pollut Res 26(11):10816-10825

Baltagi BH, Moscone F (2010) Healthcare expenditure and income in the OECD reconsidered: evidence from panel data. Econ Model 27(4): 804-811 
Bénassy-Quéré A, Marimon R, Pisani-Ferry J, Reichlin L, Schoenmaker D, Weder B (2020) 13 COVID-19: Europe needs a catastrophe relief plan. In: Mitigating the COVID Economic Crisis: Act Fast and Do Whatever, p 121

Blázquez-Fernández C, Cantarero-Prieto D, Pascual-Sáez M (2019) On the nexus of air pollution and health expenditures: new empirical evidence. Gac Sanit 33(4):389-394

Buonocore JJ, Luckow P, Norris G, Spengler JD, Biewald B, Fisher J, Levy JI (2016) Health and climate benefits of different energyefficiency and renewable energy choices. Nat Clim Chang 6(1): $100-105$

Chaabouni S, Saidi K (2017) The dynamic links between carbon dioxide $(\mathrm{CO} 2)$ emissions, health spending and GDP growth: a case study for 51 countries. Environ Res 158:137-144

Chaabouni S, Zghidi N, Mbarek MB (2016) On the causal dynamics between $\mathrm{CO} 2$ emissions, health expenditures and economic growth. Sustain Cities Soc 22:184-191

Darçın M (2017) How air pollution affects subjective well-being. Wellbeing and Quality of Life: Medical Perspective, 211

Fang K, Wang T, He J, Wang T, Xie X, Tang Y et al (2020) The distribution and drivers of PM2. 5 in a rapidly urbanizing region: the Belt and Road Initiative in focus. Sci Total Environ 716:137010

Fernando Y, Bee PS, Jabbour CJC, Thomé AMT (2018) Understanding the effects of energy management practices on renewable energy supply chains: implications for energy policy in emerging economies. Energy Policy 118:418-428

Gövdeli T (2019) Health expenditure, economic growth, and CO2 emissons: evidence from the OECD countries. Adiyaman Üniversitesi Sosyal Bilimler Enstitüsü Dergisi, (31), 488-516

Granger CWJ, Newbold P (1986) Forecasting Economic Time Series, 2d edn. Academic Press, Orlando, FL

Hansen BE, Phillips PC (1990) Estimation and inference in models of cointegration: a simulation study. Adv Econ 8(1989):225-248

Jebli MB (2016) On the causal links between health Indicator, output, combustible renewables and waste consumption, rail transport, and CO2 emissions: the case of Tunisia. Environ Sci Pollut Res 23: 16699-16715

Jebli MB, Youssef SB, Ozturk I (2016) Testing environmental Kuznets curve hypothesis: The role of renewable and non-renewable energy consumption and trade in OECD countries. Ecol Indic 60:824-831

Kais S, Sami H (2016) An econometric study of the impact of economic growth and energy use on carbon emissions: panel data evidence from fifty eight countries. Renew Sust Energ Rev 59:1101-1110

Kalim R, Shahbaz M (2009) Remittances and poverty nexus: evidence from Pakistan. Int Res J Financ Econ 29(2):45-59

Kayani GM, Ashfaq S, Siddique A (2020) Assessment of financial development on environmental effect: implications for sustainable development. J Clean Prod 120984

Khan MK, Teng JZ, Khan MI, Khan MO (2019) Impact of globalization, economic factors and energy consumption on $\mathrm{CO} 2$ emissions in Pakistan. Sci Total Environ 688:424-436

Khoshnevis Yazdi S, Khanalizadeh B (2017) Air pollution, economic growth and health care expenditure. Economic researchEkonomska istraživanja 30(1):1181-1190

Lee H, Oh DY, Meng M (2019) Stationarity and cointegration of healthcare expenditure and GDP: evidence from tests with smooth structural shifts. Empir Econ 57(2):631-652

Li Y, Chiu YH, Lin TY (2019) The impact of economic growth and air pollution on public health in 31 Chinese cities. Int J Environ Res Public Health 16(3):393

Liu M, Ren X, Cheng C, Wang Z (2020) The role of globalization in CO2 emissions: a semi-parametric panel data analysis for G7. Sci Total Environ 718:137379

Lu ZN, Chen H, Hao Y, Wang J, Song X, Mok TM (2017) The dynamic relationship between environmental pollution, economic development and public health: evidence from China. J Clean Prod 166:134-147

Ma Y, Yan J, Sha J, He G, Song C, Fan S, Ke W (2018) Dynamic simulation of the atmospheric environment improved by a focus on clean energy utilization of resource-based cities in China. J Clean Prod 192:396-410

Mărginean I (2014) Public expenditure with education and healthcare in EU countries. Procedia Economics and Finance 8:429-435

Mehrara M, Sharzei G, Mohaghegh M (2011) The relationship between health expenditure and environmental quality in developing countries. Journal of Health Administration 14(46)

Mirmirani S, Li HC, Ilacqua JA (2008) Healthcare efficiency in transition economies: an application of data envelopment analysis. International Business \& Economics Research Journal (IBER) 7(2)

Moktadir MA, Ali SM, Jabbour CJC, Paul A, Ahmed S, Sultana R, Rahman T (2019) Key factors for energy-efficient supply chains: implications for energy policy in emerging economies. Energy 189: 116129

Murthy VN, Okunade AA (2016) Determinants of US health expenditure: evidence from autoregressive distributed lag (ARDL) approach to cointegration. Econ Model 59:67-73

OECD Health Statistics (2019) https://www.oecd.org/health/health-data. htm

Omri A, Nguyen DK, Rault C (2014) Causal interactions between CO2 emissions, FDI, and economic growth: evidence from dynamic simultaneous-equation models. Econ Model 42:382-389

Özçiçek Ö, Ağpak F (2017) The role of education on renewable energy use: evidence from Poisson pseudo maximum likelihood estimations. J Bus Econ Policy 4(4):49-61

Pablo-Romero MDP, Román R, Sánchez-Braza A, Yñiguez R (2016) Renewable energy, emissions, and health. Renewable Energy: Utilisation and System Integration, 173

Rehman MU (2020) Dynamic correlation pattern amongst alternative energy market for diversification opportunities. J Econ Struct 9(1): $1-24$

Ross CE, Wu CL (1995) The links between education and health American Sociological Review:719-745

Saidi K, Hammami S (2016) Economic growth, energy consumption and carbone dioxide emissions: recent evidence from panel data analysis for 58 countries. Qual Quant 50(1):361-383

Sekar C, Gurjar BR, Ojha CSP, Goyal MK (2016) Potential assessment of neural network and decision tree algorithms for forecasting ambient PM 2.5 and CO concentrations: case study. Journal of Hazardous, Toxic, and Radioactive Waste 20(4):A5015001

Tran H, Kim J, Kim D, Choi M, Choi M (2018) Impact of air pollution on cause-specific mortality in Korea: results from Bayesian model averaging and principle component regression approaches. Sci Total Environ 636:1020-1031

Usman M, Ma Z, Wasif Zafar M, Haseeb A, Ashraf RU (2019) Are air pollution, economic and non-economic factors associated with per capita health expenditures? Evidence from emerging economies. Int J Environ Res Public Health 16(11):1967

Varabyova Y, Müller JM (2016) The efficiency of healthcare production in OECD countries: a systematic review and meta-analysis of crosscountry comparisons. Health Policy 120(3):252-263

Wang KM, Lee YM, Lin CL, Tsai YC (2018) The effects of health shocks on life insurance consumption, economic growth, and health expenditure: a dynamic time and space analysis. Sustain Cities Soc $37: 34-56$

Wang Z, Asghar MM, Zaidi SAH, Wang B (2019) Dynamic linkages among CO 2 emissions, health expenditures, and economic growth: empirical evidence from Pakistan. Environ Sci Pollut Res 26(15): 15285-15299

Wang S, Gao S, Li S, Feng K (2020) Strategizing the relation between urbanization and air pollution: empirical evidence from global countries. J Clean Prod 243:118615 
Xie Y, Dai H, Dong H (2018) Impacts of SO2 taxations and renewable energy development on $\mathrm{CO} 2$, NOx and $\mathrm{SO} 2$ emissions in Jing-Jin-Ji region. J Clean Prod 171:1386-1395

Yao W, Gao D, Sheng P (2019) The impact of education on healthcare expenditure in China: quantity or quality. Appl Econ Lett 26(14): $1192-1195$

Ye L, Zhang X (2018) Nonlinear Granger causality between healthcare expenditure and economic growth in the OECD and major developing countries. Int J Environ Res Public Health 15(9):1953
Zaidi S, Saidi K (2018) Environmental pollution, health expenditure and economic growth in the sub-Saharan Africa countries: panel ARDL approach. Sustain Cities Soc 41:833-840

Publisher's note Springer Nature remains neutral with regard to jurisdictional claims in published maps and institutional affiliations. 